\title{
ULTRASOUND -GUIDED INTERSCALENE BRACHIAL PLEXUS PLUS DISTAL MEDIAN AND ULNAR NERVE BLOCK IN A PATIENT WITH COMPLEX REGIONAL PAIN SYNDROME TYPE I
}

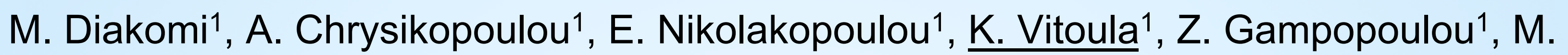
Konstantinidou'1.

${ }^{1}$ General Hospital of Attica "KAT", Pain Evaluation and Therapy Center, Athens, Greece.

\section{Background and Aims:}

The "Budapest consensus definition" describes Complex Regional Pain Syndrome (CRPS) as "an array of painful conditions characterized by a continuing regional pain that is seemingly disproportionate in time or degree to the usual course of any known trauma or other lesion". In particular, CRPS type I refers to patients with CRPS without evidence of peripheral nerve injury. A wide variety of treatment modalities have been described in the latest systematic review, suggesting readers to continue investigating possible treatments for CRPS.

\section{Methods:}

A 50-year-old female presented in our pain department with CRPS type I of the right upper limb producing a frozen shoulder. Severe pain and swelling in the right arm, wrist and hand, which had started within 4 months following a fracture in the humerus, affected functionality and quality of life.
After explaining the procedure to the patient and having obtained informed consent, we performed ultrasound (US)guided interscalene Brachial Plexus block (15 $\mathrm{ml}$ ropivacaine $0,2 \% / 8 \mathrm{mg}$ dexamethasone) followed by US-guided median and ulnar nerve block at the level of the mid forearm (5 $\mathrm{ml}$ ropivacaine $0,2 \%$ to block each nerve $/ 30 \mu \mathrm{g}$ clonidine).

\section{Results}

The patient reported immediate pain relief. The patient is on a weekly phone follow up for already 30 days and reports decreased oedema and pain scores in the affected extremity.

\section{Conclusions:}

Complex Regional Pain Syndrome, as a chronic pain disorder, requires a multimodal approach, including brachial plexus blocks. Ultrasound guidance has made distal nerve blocks of the upper limb a safe and efficacious tool to provide effective analgesia.
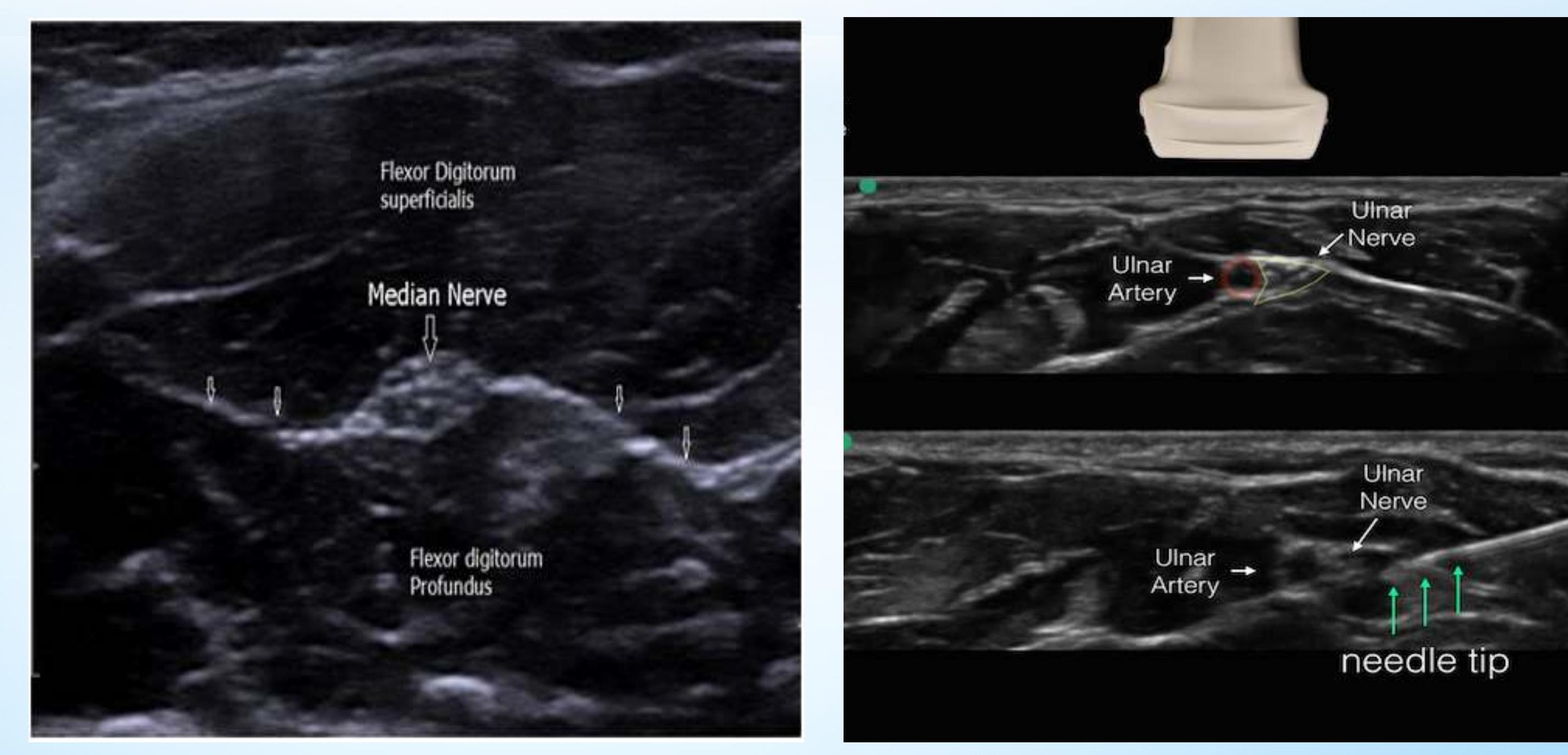